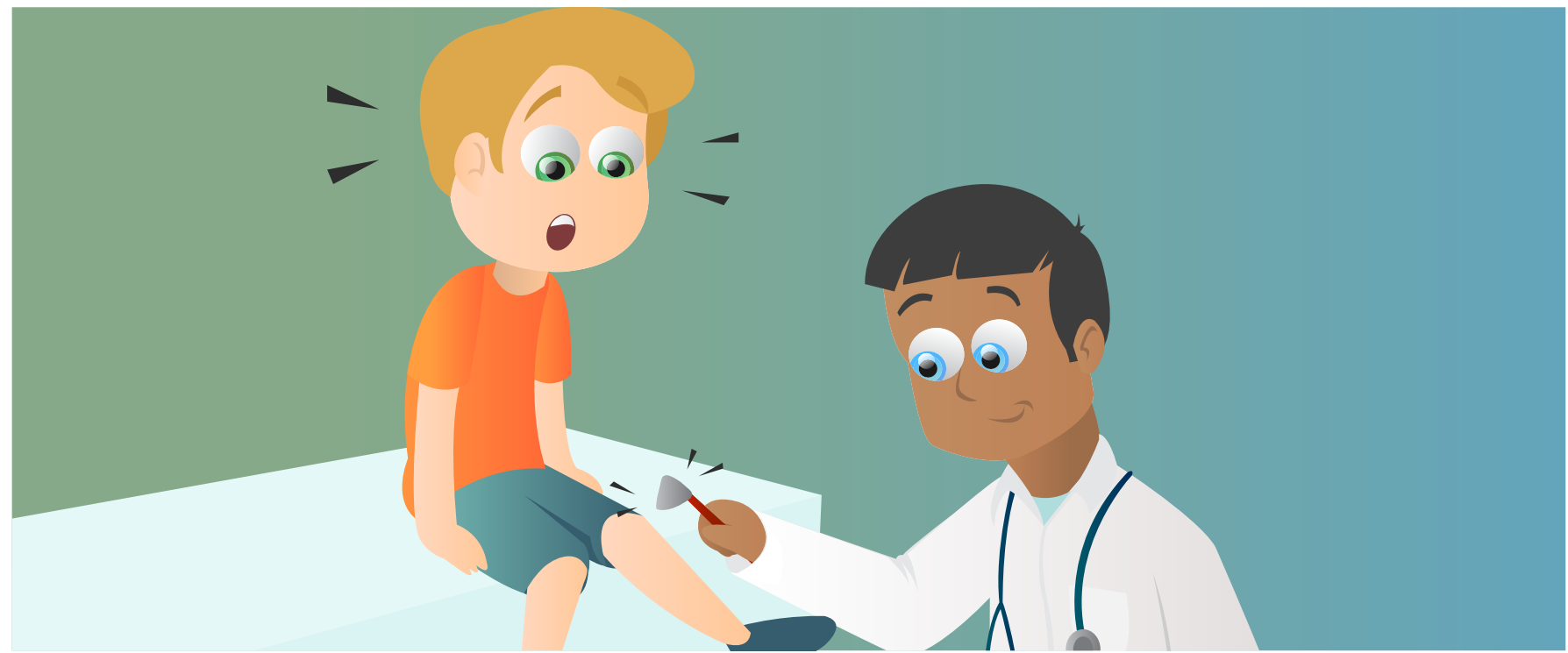

\title{
WHEN KICKING THE DOCTOR IS GOOD-A SIMPLE REFLEX
}

\section{Jennifer M. Jakobi*, Sienna Kohn, Samantha Kuzyk and Andrey Fedorov}

Healthy Exercise and Aging Lab, School of Health and Exercise Sciences, University of British Columbia Okanagan, Kelowna, BC, Canada

REVIEWED BY:

FRANCISCO

15 YEARS OLD
Humans and animals have reflexes to help protect them from danger. Reflexes are unconscious responses, which means they are automatic and do not require the brain to create the action. There are many different types of reflexes, but the most basic is called a simple reflex. A simple reflex contains only one space where information in the spinal cord travels between two nerve cells, called neurons. The space between two neurons is called a synapse. Thus, a simple reflex is called monosynaptic, where "mono" means "one." There are four parts to a monosynaptic simple reflex. The first is a sensor, which senses what is happening to the body, the second is a sensory neuron to carry that information to the spinal cord, and the third is a motor neuron to transmit information away from the spinal cord to the fourth part, which is the muscle that creates an action. Doctors will test reflexes by tapping the tendon just below the knee, and this causes the leg to kick out. This knee-jerk reflex is an example of a simple monosynaptic reflex.

Have you ever noticed that when you touch a sharp or hot object, you pull your hand away rapidly without even thinking about the action? This reaction of removing your hand very quickly is a natural response within your 


\section{REFLEXES}

An unconscious (without involving the brain) reaction in the body to a stimulus.

ACTION POTENTIAL.

A signal that is carried from one neuron to another.

NEURON

An excitable cell. body, designed to protect you [1]. This quick response is called a reflex, and reflexes occur without conscious thinking or planning, meaning the brain is not involved in them. This is very different than most behaviors that you do every day, such as playing Lego, combing your hair, cutting your food, or fist bumping, which all involve using the brain. The major difference is that reflexes just happen - they occur very quickly and without your brain's input. Actually, many reflexes are even faster than the blink of an eye!

\section{BUILT FOR PROTECTION}

Although reflexes are super-fast and just happen without you thinking about them, this does not mean that they are bad. Reflexes protect you and allow you to move around without thinking about every single action and response your body needs to make. It is important that reflexes occur without the need for thinking about them because there are things that happen to your body and forces acting in your body when you move that need to be responded to very quickly. Reflexes allow your body to react in ways that help you to be safe, to stand upright, and to be active.

Imagine a typical day. You might be thinking of practicing your sport or musical instrument, walking to school, or making a snack. In all of these actions, you are thinking, but at the same time, there are also reflexes that you are unaware of happening inside your body. These reflexes are built naturally into the body, and they exist at birth and change as we grow older. Reflexes are kind of like safety features for survival that allow us to move in response to something in the environment. Reflexes can act to protect you in many ways, including removing your hand from a hot or sharp object, or ducking when a loud and sudden sound occurs. These fast actions are reflex responses! The fact that these responses are automatic shows that reflexes occur at a rate that is far too fast for the brain to be involved with the response. Actions that occur without the involvement of the brain are called involuntary actions, while planned actions from the brain, like throwing a ball or strumming a guitar, are called voluntary actions. After the reflex action has happened, the brain does become aware and tells you what happened. At this point, the brain might even add to the action. For example, you might have ducked as an involuntary response to a very loud noise, but when the brain becomes involved you learn why you ducked down and the brain sends the voluntary action to respond-maybe to stand back up.

\section{THE ACTION POTENTIAL}

In order for reflexes to work, messages need to move around the body. These messages are action potentials, and they travel along the neurons and send messages, special parts of the neurons are involved. The neuron has three different parts that allow signals to be sensed, to travel, and then move to another neuron or muscle. These three parts are called the dendrites, the 


\section{FIGURE}

Diagram of a neuron, showing the place where the action potential start (dendrites), the path it travels along (axon), and where it ends (nerve endings), before moving across the synapse to another neuron or muscle.

\section{MOTOR NEURON}

A neuron that goes from the spinal cord to the muscle.

\section{SENSORY NEURON}

A neuron that goes from receptors to the spinal cord.

MONOSYNAPTIC

\section{REFLEX}

A reflex that only contains one space for an action potential to travel between a sensory and motor neuron.

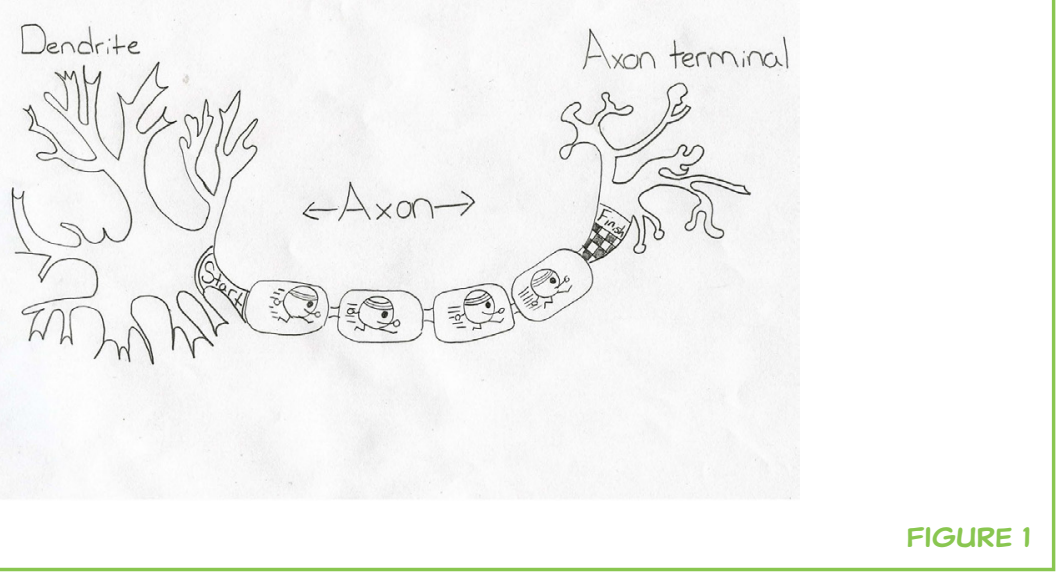

axon, and the nerve ending (Figure 1). The dendrites receive information from the sensor or other neurons. This information then moves to the axon, which travels to or from the spinal cord. The action potential travels from the nerve endings at one end of the neuron to the next neuron. Many reflexes start at the muscle or skin and go to the spinal cord. When the action potential reaches the nerve ending, the signal is transferred to another neuron, such as an interneuron or motor neuron. The action potential then travels outside the spinal cord to a muscle. It doesn't matter whether the neuron is a sensory neuron, an interneuron, or a motor neuron-the action potential travels from the dendrites to the axon to the nerve endings. But the neurons do not touch each other in the spinal cord and do not touch at the muscle. There are tiny spaces called synapses that the action potential must jump across.

\section{WORKING PARTS OF A REFLEX}

Doctors will perform a test to make sure reflexes are working properly because reflexes can change if you are sick and as you grow. Imagine you are sitting up on the exam table and the doctor taps you just below the knee with a rubber hammer. Right after the tap, your foot kicks out and you didn't even try to do it. Hopefully, the doctor moved out of the way! The response to the tap of the rubber hammer is called a knee-jerk reflex, but scientists and doctors call it a monosynaptic reflex - the simplest reflex that occurs inside your body [2]. You may be wondering why it's called monosynaptic because knee-jerk is easier to remember and spell. Monosynaptic is an important word because it describes how the reflex works. When broken into two parts, the word is easier to remember. "Mono" means one. "Synapse" just means a space between two neurons where the message transfers between them. That means, in the knee-jerk reflex, there is only one point where the message transfers between neurons, so it is monosynaptic. This monosynaptic reflex is called simple because it works through 


\section{RECEPTOR}

A part of skin or muscle that senses a stimulus.

\section{FIGURE 2}

Knee-jerk reflex.

The tendon is tapped as the first step in the action.

The doctor tapping just below the knee activates a sensor that is located inside the muscle. Once the sensor is activated, the signal travels along the sensory neuron to the spinal cord. In the spinal cord, the signal crosses a synapse to a motor neuron and then travels back to the same muscle.

This muscle contracts and causes the leg to kick forward. only four separate parts, whereas most reflexes work through five parts. The five parts of most reflexes are:

- A sensor, which is a receptor that senses or detects a change.

- A sensory neuron (nerve cell) that carries the message from the sensor to the spinal cord.

- An interneuron, which is an in-between neuron, like a relay station between neurons.

- A motor neuron that carries the message from the spinal cord to the muscle.

- A muscle fiber that contracts.

The monosynaptic knee-jerk reflex skips the interneuron, so it involves the sensor, sensory neuron, motor neuron, and muscle fiber (Figure 2). In a monosynaptic reflex, the message travels from the sensory neuron to the motor neuron with only one synapse. If you think about a relay race with a baton, this is similar to the way a reflex works. The runner with the baton is the action potential, and it is carried down the neuron, which is part of the track. When the runner and baton get to a specific area on the track, the baton is transferred to the next runner to move along the track. A reflex is just like a relay race, but in a reflex, it is the action potential that moves between neurons rather than a baton and runner along parts of the track (Figure 3 ).

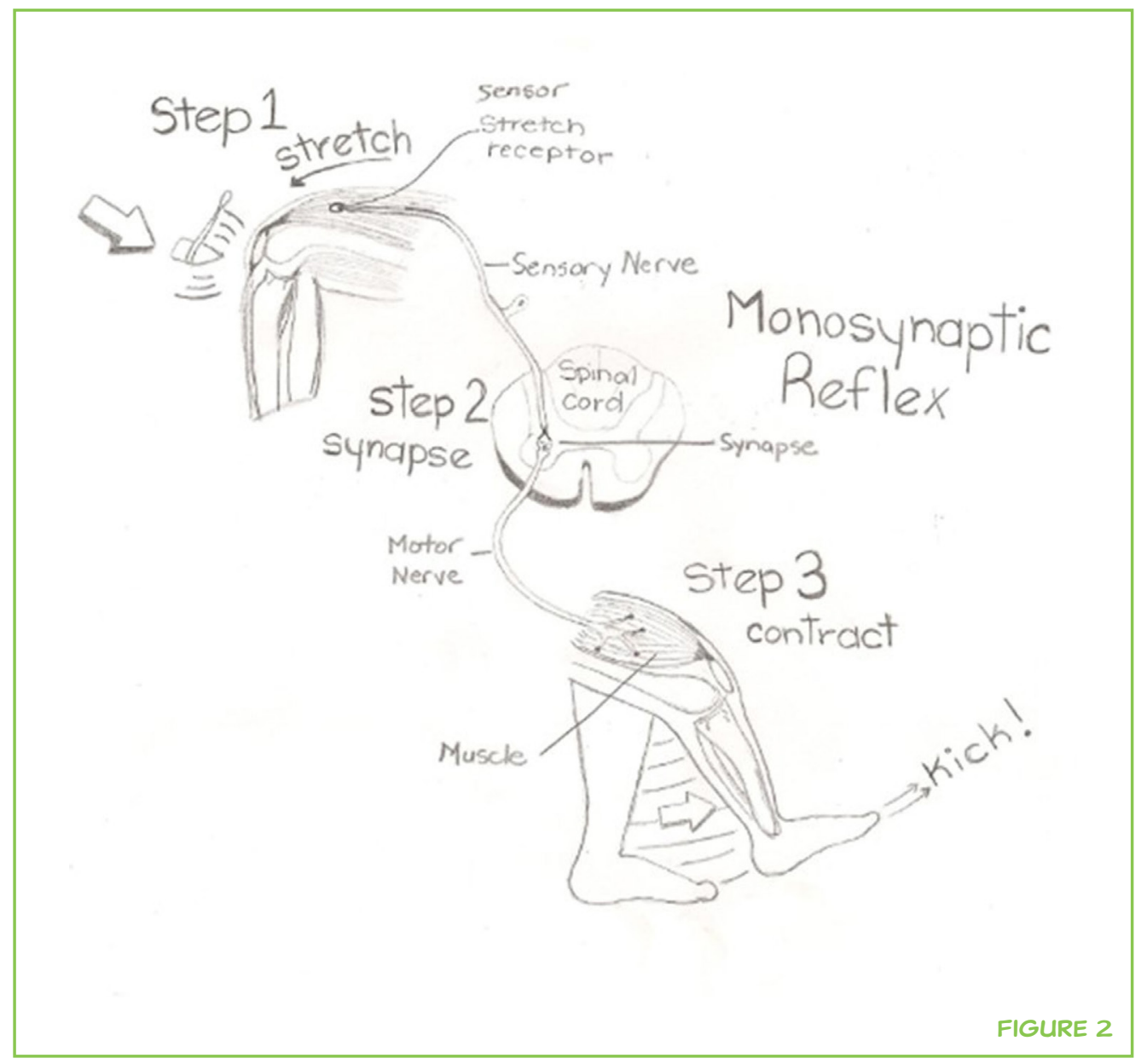




\section{FIGURE 3}

Reflex path showing the five components of a reflex: sensor, sensory neuron, interneuron, motor neuron, and muscle. The simple reflex is shown on the inner part of the diagram. Action potentials are how information is transmitted in the nervous system. In a reflex, the information is first detected in the sensor and travels along sensory neurons to the spinal cord. Once the action potential reaches the spinal cord, the information is transmitted across the synapse to the motor neuron. The action potential then travels down the motor neuron to the muscle, which then performs the action. The outer part of the diagram, within the spinal cord, shows the fifth part of reflexes, the interneuron.

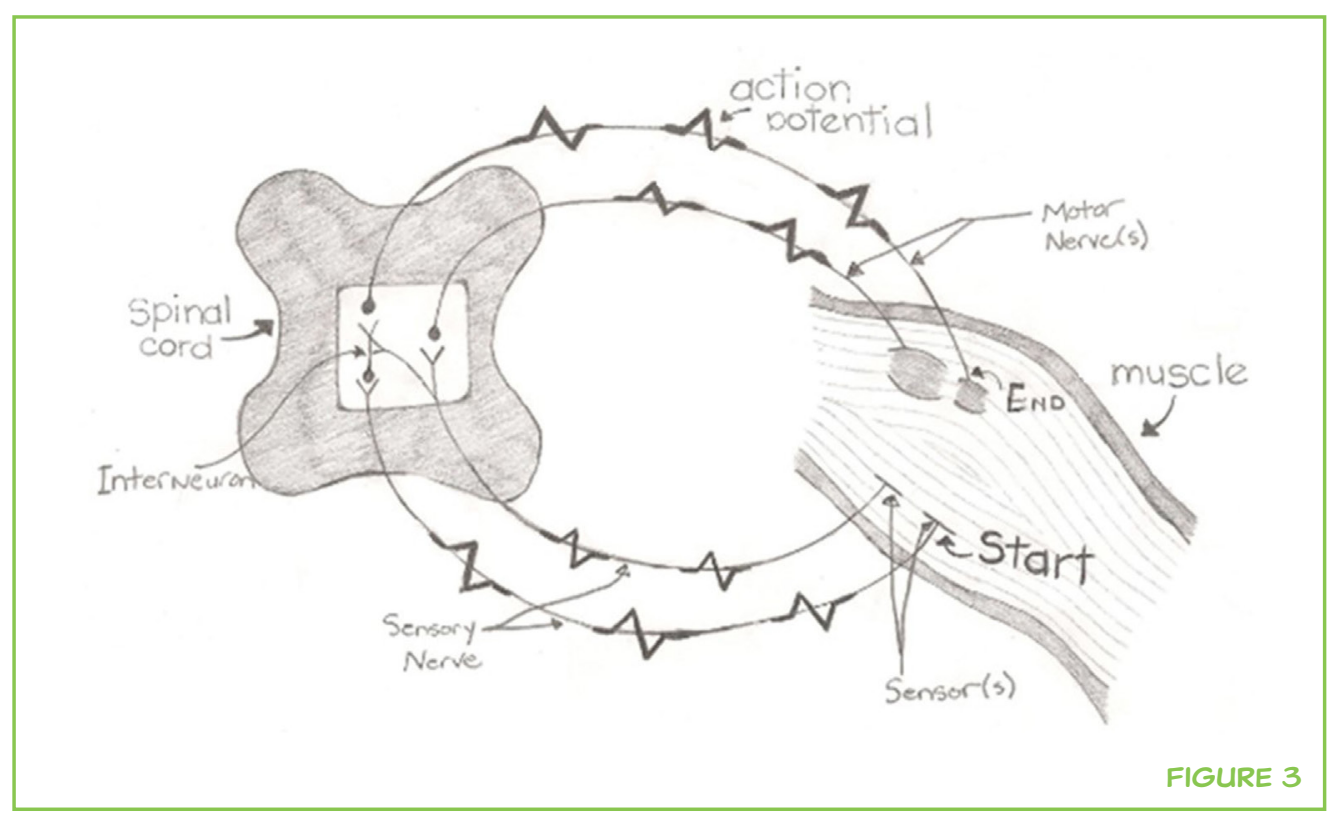

In the above example of a monosynaptic reflex, the interneuron is not used. It is easy to add an interneuron; just add another runner and baton, but this runner travels a very short distance. In our body, interneurons are in the spinal cord. So, when an interneuron participates in a reflex, there is more than one synapse, and these reflexes are then called complex reflexes.

\section{NOT ALL REFLEXES ARE SIMPLE}

There are many different reflexes in the body. Some of them are complicated and involve multiple interneurons and many synapses. When there are many synapses, the reflex is called polysynaptic ("poly" means many). These reflexes, just like the simple monosynaptic reflex, exist in living beings, especially humans, to keep us safe! Sometimes reflexes create more than one action. Imagine removing your foot from something sharp-like a Lego piece that was left on the floor. If you removed your foot from the Lego because it hurt, but didn't place your other foot down, you would fall and that would hurt even more! So, the withdrawal reflex to remove your foot works with a reflex on the other side of the body telling you to put your other foot down. That reflex is called the crossed extensor reflex. These actions are all done without you thinking or planning, but your brain helps to assess the situation as an afterthought. It might think, "That hurt! Who left the Lego there?"

\section{WHAT DOES THE BRAIN DO?}

Did you notice how the brain was not on the five-part list of what makes up a reflex? Well, reflexes are functions of the nervous system, which coordinates our actions. The nervous system is the network of neurons that transmits the 
POLYSYNAPTIC REFLEX

A complex reflex that contains many connections between neurons. action potentials. The sensor and neurons are outside the spinal cord, in what is called the peripheral nervous system (PNS). The other part of the system is called the central nervous system (CNS), and it consists of the brain and spinal cord. The CNS is used to think, plan, and learn. The CNS interacts with the PNS, including the reflexes. Remember the earlier examples when you ducked down in response to a loud noise or lifted your foot after stepping on the Lego? In those examples, the CNS is what helped you understand what the noise was or why you moved automatically. It did not create the initial movement, but the CNS allowed you to understand why you ducked down or that you stepped on a Lego. The CNS also plans the voluntary movements that come after the initial involuntary reflex. Perhaps you will bend down and pick up the Lego-that is a voluntary movement.

\section{SUMMARY}

Do you remember the example of the doctor tapping your knee? That is a test to see how well your body is prepared to react. There are many different types of reflexes that protect your body. The doctor tapping your tendon is a test of the simple monosynaptic reflex, which consists of a sensor, a sensory neuron, a motor neuron, and a muscle. Once the sensory neuron is activated, an action potential travels along the sensory neuron to the spinal cord. The action potential then moves across the synapse to a motor neuron and leaves the spinal cord. More advanced reflex responses will use an interneuron, and these are called polysynaptic reflexes. Reflexes do not involve the CNS at first, but after the reflex has occurred in the body to keep it safe, the brain assists in understanding what happened. Although we do not think about reflexes, they are important parts of our nervous system.

\section{ACKNOWLEDGMENTS}

The authors sincerely thank and recognize Miss. Jenna Cooper, a student at Vernon Secondary School, for her art work contributions. The authors thank Mr. Jakob Jones, a student at École Beairsto Elementary, and Mrs. Heather Jakobi, Vice Principle Arthur Voaden Secondary School, for comments on an earlier draft.

\section{REFERENCES}

1. Perenboom, M. J. L., Van de Ruit, M., De Groot, J. H., Schouten, A. C., and Meskers, C. G. M. 2015. Evidence for sustained cortical involvement in peripheral stretch reflex during the full long latency reflex period. Neurosci. Lett. 584:214-8. doi:10.1016/j.neulet.2014.10.034

2. Chen, H., Hippenmeyer, S., Arber, S., and Frank, E. 2003. Development of the monosynaptic stretch reflex circuit. Curr. Opin. Neurobiol. 13:96-102. doi:10.1016/ S0959-4388(03)00006-0 
SUBMITTED: 12 October 2016; ACCEPTED: 23 March 2017;

PUBLISHED ONLINE: 28 April 2017.

EDITED BY: Rich Ivry, University of California, Berkeley, USA

CITATION: Jakobi JM, Kohn S, Kuzyk S and Fedorov A (2017) When Kicking the Doctor is Good-A Simple Reflex. Front. Young Minds 5:10. doi:10.3389/frym.2017.00010

CONFLICT OF INTEREST STATEMENT: The author declares that the research was conducted in the absence of any commercial or financial relationships that could be construed as a potential conflict of interest.

COPYRIGHT (C) 2017 Jakobi, Kohn, Kuzyk and Fedorov. This is an open-access article distributed under the terms of the Creative Commons Attribution License (CC BY). The use, distribution and reproduction in other forums is permitted, provided the original author(s) or licensor are credited and that the original publication in this journal is cited, in accordance with accepted academic practice. No use, distribution or reproduction is permitted which does not comply with these terms.

\section{REVIEWED BY}

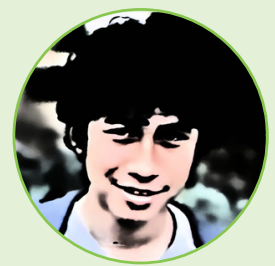

\section{FRANCISCO, 15 YEARS OLD}

My name is Francisco and I am a high school student living in the Bay Area. My favorite subject and area of learning is science, and I play squash as a sport. When I'm not working, I can be found drawing and cooking.

\section{AUTHORS}

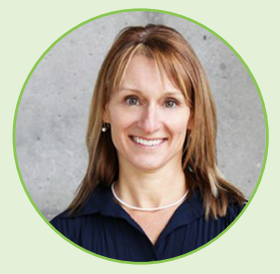

\section{JENNIFER M. JAKOBI}

Jennifer M. Jakobi is an Associate Professor in the School of Health and Exercise Science at the University of British Columbia Okanagan. She is a Neuroscientist who studies how men and women age differently. As Director of the integrative STEM Team Advancing Networks of Diversity (iSTAND) program, she organizes and hosts Neuroscience Camps for youth that integrate coding and engineering into human movement neuroscience. *jennifer.jakobi@ubc.ca

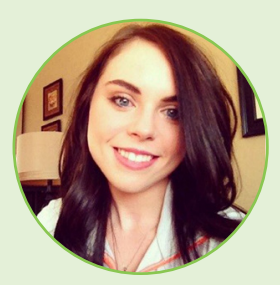

\section{SIENNA KOHN}

Sienna Kohn is a fourth year human kinetics major and psychology minor at the University of British Columbia Okanagan. She is an active student researcher in neuromuscular physiology and student leader in the iSTAND program. She has a passion for health and fitness, particularly in the anatomy and physiology realm. Her research is evaluating the elastic-like characteristics of the tendon.

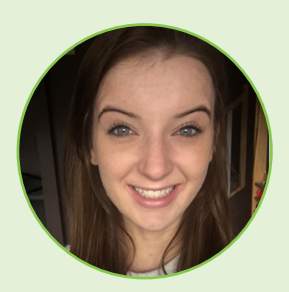

\section{SAMANTHA KUZYK}

Samantha Kuzyk is a first year MSc Student in Interdisciplinary Graduate Studies at the University of British Columbia Okanagan. She has actively led the iSTAND neuroscience outreach camps as well as conducted research in the Healthy Exercise and Aging Lab. Her research interests involve how the tendon adapts to movement and vibration. Her passions 
involve helping people and learning more about the human body. She fell in love with research because of the potential it offers in helping people to move well into old age through her research findings.

\section{ANDREY FEDOROV}

Andrey Fedorov is a fourth year Human Kinetics student. He loves learning and studying all things related to the human body. He is consistently applying what he learns in the laboratory to sports and to his work with children at the local Boys and Girls Clubs and in the iSTAND program. His interests involve looking at how the muscle and tendon are effected by movement. 